\title{
Splice site selection and ribonucleoprotein complex assembly during in vitro pre-mRNA splicing
}

\author{
Kristin K. Nelson and Michael R. Green \\ Department of Biochemistry and Molecular Biology, Harvard University, Cambridge, Massachusetts 02138 USA
}

To study the determinants of splice site selection, we have inserted synthetic $5^{\prime}$ and $3^{\prime}$ splice sites at different positions within $\beta$-globin genes and analyzed the resultant RNA substrates for in vitro splicing, factor binding, and complex assembly. We show that consensus $5^{\prime}$ and $3^{\prime}$ splice site sequences are insufficient to determine splice site utilization; in the presence or absence of the authentic site, the synthetic sites are variably active in a position-dependent manner. However, regardless of position or utilization, the synthetic $5^{\prime}$ and $3^{\prime}$ splice sites are bound by the appropriate splicing factors. Thus, binding of splicing factors is necessary but not sufficient for splice site utilization. Finally, we demonstrate that a block to efficient splicing can occur at multiple steps in the pathway of normal splicing complex assembly.

[Key Words: Pre-mRNA splicing; splice site selection; ribonucleoprotein complexes; U1 snRNP; 70-kD RBP]

Received November 9, 1987; revised version accepted January 13, 1988.

Since the discovery of pre-mRNA splicing, significant progess has been made in identifying the components of the splicing machinery and determining the general pathway of the reaction (for reviews, see Green 1986; Padgett et al. 1986; Maniatis and Reed 1987; Sharp 1987). Less has been learned about the determinants of splice site recognition and selection. Early sequence comparisons identified highly conserved sequences at the intron boundaries, and consensus splice junctions sequences were proposed (Mount 1982; Green 1986; Padgett et al. 1986). The $5^{\prime}$ splice site consensus is a well defined sequence, CAG/GTAAGT. The $3^{\prime}$ splice site consensus, generally written as PynNPyAG/G, is less precise and contains two functional elements, an AG dinucleotide at the 3 ' splice junction, preceded by a pyrimidine-rich region referred to as a polypyrimidine tract (Mount 1982). Mutational studies have demonstrated the importance of these consensus elements; mutations in these regions abolish or reduce accurate splicing and frequently activate cryptic splice sites, which resemble authentic splice junction sequences (Treisman et al. 1983; Green 1986; Padgett et al. 1986).

These sequence elements are recognized and function by interacting with splicing factors. The $5^{\prime}$ splice site base-pairs with the $5^{\prime}$ end of the U1 small nuclear RNA (snRNA) (Zhuang and Weiner 1986). The consensus 5' splice site, 5'-CAG/GTAAGT-3', is perfectly complementary to the $5^{\prime}$ end of U1 snRNA whereas $96 \%$ of natural 5' splice sites have one to several mismatches (Mount 1982; Ohshima and Gotoh 1987). Recognition of the $3^{\prime}$ splice site is not fully understood although several factors that bind to the $3^{\prime}$ splice site region have been identified (Gerke and Steitz 1986; Tazi et al. 1986; Ruskin et al. 1988).

The major unsolved problem in splice site selection is why sequences within exons and introns that conform to consensus splice sites are normally inactive. There is a body of evidence that suggests the exon and intron sequences flanking the consensus splice junctions play a role (Pikielny and Rosbash 1985; Somasekhar and Mertz 1985; Reed and Maniatis 1986; Furdon and Kole 1986), although conserved sequences within these flanking regions have not been identified. Several recent studies suggest that complementarity to U1 snRNA is a major determinant of $5^{\prime}$ splice site selection. Increasing the complementarity of an alternative splice site can dramatically increase its use (Zhuang et al. 1987). Similarly, decreasing the complementarity of a normal $5^{\prime}$ splice site can activate a cryptic site (Aebi et al. 1987). A recent computer study supports the importance of complementarity of the $5^{\prime}$ splice site to U1 snRNA; in $79 \%$ of cases studied, the normal $5^{\prime}$ splice site is more complementary than any other sequence within the flanking exon and intron (Ohshima and Gotoh 1987). These results suggest that $5^{\prime}$ splice site selection may be predominantly based on complementarity to U1 snRNA.

To test if match to the presently defined splice site consensus sequence is in fact the primary or sole determinant of splice site selection, and to explore further the role of flanking sequences, we have constructed a series of splice site insertion mutants by inserting synthetic $5^{\prime}$ and $3^{\prime}$ splice sites into various positions within rabbit 
and human $\beta$-globin genes. The analysis of these mutants demonstrates that splice site selection is apparently less dependent on match to the consensus than on the context in which the splice site resides. However, within the context of the authentic site, match to the consensus sequence is a critical determinant of $5^{\prime}$ splice site selection. Furthermore, a consensus $5^{\prime}$ splice site is less context dependent than a splice site that deviates from the consensus sequence. Surprisingly, regardless of usage, inserted $5^{\prime}$ splice sites are bound by U1 snRNP. Synthetic 3 ' sites behave similarly; although bound by a splicing factor in all instances, the site is functional only when near the authentic site. Thus, while binding of splicing factors to their cognate sites is necessary, it is not sufficient for splice site selection.

\section{Results and discussion}

\section{General strategy}

Two $5^{\prime}$ splice sites were synthesized for construction of $5^{\prime}$ splice site insertion mutants. The first $\left(5^{\prime}\right.$-CAG) GTAAGT-3'), which we refer to as the consensus $5^{\prime}$ splice site, is an exact match to the consensus $5^{\prime}$ splice site sequence (Mount 1982; Green 1986; Padgett et al. 1986). The second (5'-AGG/GTGAGT- $\left.3^{\prime}\right)$, which we refer to as the rabbit $5^{\prime}$ splice site, is the actual rabbit $\beta$-globin IVS2 $5^{\prime}$ splice site. Because the $3^{\prime}$ splice site consensus is not rigidly defined we used a modified human $\beta$-globin IVS1 $3^{\prime}$ splice site $\left(5^{\prime}\right.$ GCCCTCTATTTTCCCACCCTTAG/G-3') as the synthetic 3' splice site.

In the appropriate context a consensus $5^{\prime}$ splice site is active and binds U1 snRNP at high levels

To determine whether the match of a potential $5^{\prime}$ splice site to the consensus is the primary determinant of selection, our initial strategy was to test the activity of the synthetic consensus $5^{\prime}$ splice site inserted at various positions within globin genes. However, we noted that a $5^{\prime}$ splice site that precisely matches the consensus occurs very rarely in natural genes $(3.6 \%$; Mount 1982$)$. Therefore, we considered that the consensus $5^{\prime}$ splice site might be inefficient or inactive and hence selected against. To examine this possibility, we compared the activity of a consensus $5^{\prime}$ splice site to an efficiently used normal 5' splice site. By site-directed mutagenesis (Taylor et al. 1985) we converted the human $\beta$-globin IVS1 $5^{\prime}$ splice site $\left(5^{\prime}\right.$-CAG/GTTGGT- $\left.3^{\prime}\right)$ to the $5^{\prime}$ splice site consensus $\left(5^{\prime}\right.$-CAG/GTAAGT- $3^{\prime}$; $\mathrm{H} \beta^{5^{\prime} \mathrm{C}}$ mutant; Fig. 1A). The $\mathrm{H} \beta^{5^{\prime} \mathrm{C}}$ pre-mRNA is spliced only slightly less efficiently than the wild-type pre-mRNA in vitro (Fig. 1A; $\mathrm{H} \beta^{5^{\prime}} \mathrm{C}$, demonstrating that a consensus $5^{\prime}$ splice site is functional. Next, we compared binding of U1 small nuclear ribonucleoprotein (snRNP) to the authentic and consensus $5^{\prime}$ splice sites using an RNase T1 protection/immunoprecipitation assay (Black et al. 1985; Chabot et al. 1985). The identity of the RNase T1resistant fragments was determined by complete RNase
$\mathrm{Tl}$ and RNase A digestion analyses (data not shown) (Fig. 1B). Significantly, the mutagenized site, which has perfect complementarity to the $5^{\prime}$ end of U1 snRNA, binds U1 snRNP at least 10-fold more efficiently than the normal site (Fig. 1B). These results demonstrate that: (1) U1 snRNP binding is not the rate-limiting step for in vitro pre-mRNA splicing; and (2) as expected (Zhuang and Weiner 1986), complementarity of the $5^{\prime}$ splice site to Ul snRNA is a major determinant of Ul snRNP binding efficiency.

\section{Analysis of synthetic 5' splice site utilization in the presence of the authentic $5^{\prime}$ splice site}

The rabbit and consensus synthetic $5^{\prime}$ splice sites were inserted into $R \beta 2 \mathrm{~K}$ at two positions in intron and two positions in exon 2 . The $\mathrm{E}$ and $\mathrm{B}$ sites are within exon 2, 55 and 18 nucleotides upstream of the authentic $5^{\prime}$ splice site, respectively. The $\mathrm{N}$ and $\mathrm{K}$ sites are in the intron, 117 and 251 nucleotides downstream of the authentic 5 ' splice site (Fig. 2A). To determine the activity of the inserted $5^{\prime}$ splice sites, the resultant pre-mRNAs were spliced in vitro and the RNA processing products compared to those generated from the wild-type premRNA. Selection of the inserted $5^{\prime}$ splice sites results in RNA processing products of sizes different from those produced from the wild-type pre-mRNA. For $5^{\prime}$ splice site insertions, this is most readily ascertained by noting the size (or sizes) of the linear exon intermediate RNA species. In contrast, if the synthetic $5^{\prime}$ splice sites are inactive, the RNA processing products are similar to those generated from the normal pre-mRNA. (The sizes of some RNA processing products are increased due to the insertion.)

In the presence of the authentic 5' splice site, utilization of either synthetic $5^{\prime}$ splice site in the $\mathrm{E}$ (Fig. 2A), N, or $\mathrm{K}$ (Fig. $2 \mathrm{C}$ ) sites is undetectable and the authentic site is used with normal efficiency. In contrast, insertion of the synthetic $5^{\prime}$ splice sites in the B site results in a dramatic decrease in overall splicing efficiency, and the two synthetic sites are utilized, but produce different splicing patterns (linear exon intermediate produced by the use of the inserted sites are marked by a star in Fig. 2A). In the case of the consensus $5^{\prime}$ splice site insertion $(\mathrm{CB} 1+)$, the synthetic site is used exclusively. When the rabbit $5^{\prime}$ splice site is inserted in the B site $(\mathrm{RB} 1+)$, however, both the synthetic and authentic $5^{\prime}$ splice sites are used equally.

Interestingly, tandem duplications of the synthetic consensus and rabbit $5^{\prime}$ splice sites in the $\mathrm{B}$ site produce different results. When two copies of the consensus site are in the $B$ site $(C B 2+)$, there is no detectable splicing. As a control, when two copies of the synthetic $5^{\prime}$ splice site are inserted in the opposite orientation, the RNA substrate uses the authentic $5^{\prime}$ splice site at wild-type efficiency (not shown). Thus, the block to splicing in $\mathrm{CB} 2+$ is due to the inserted consensus $5^{\prime}$ splice sites and not simply the insertion of 18 nucleotides. When two copies of the rabbit 5 ' splice site are inserted in the B site $(\mathrm{RB} 2+1$, the overall efficiency of splicing is slightly de- 
A

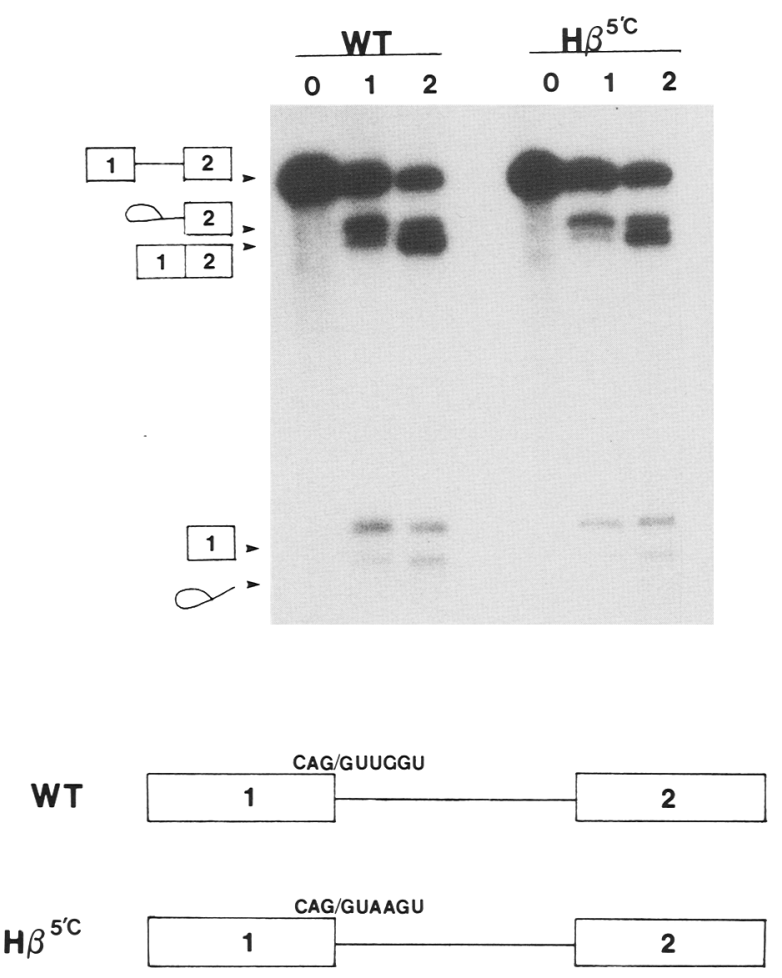

B

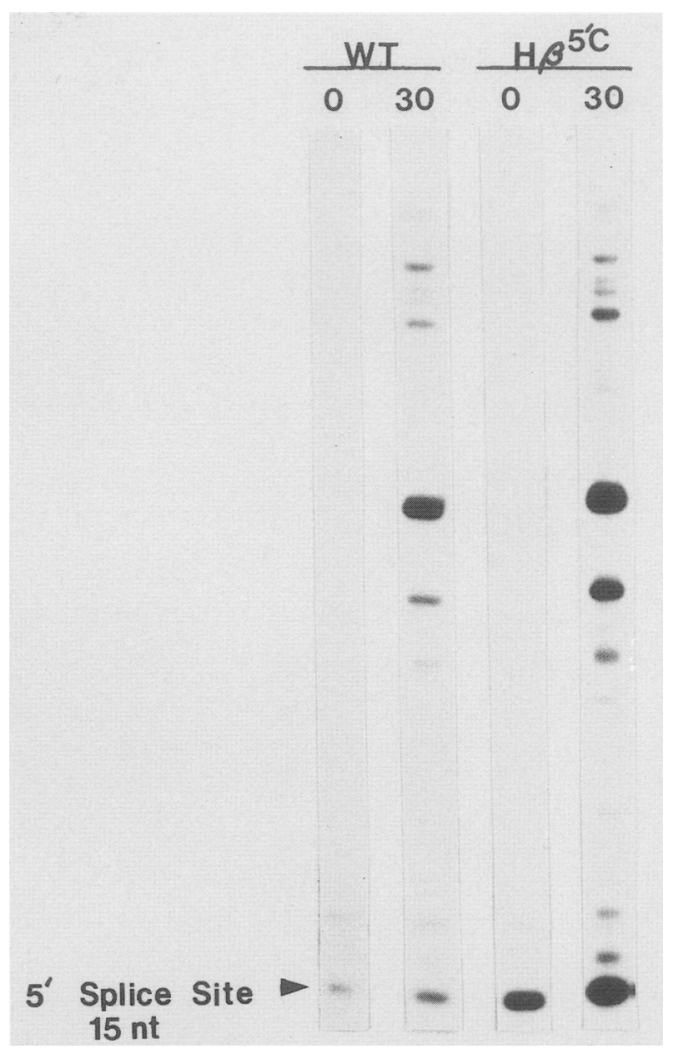

Figure 1. Analysis of the human $\beta$-globin ${ }^{5^{\prime} \mathrm{C}}$ pre-mRNA. (A) Splicing time course. Uniformly ${ }^{32} \mathrm{P}-$-labeled pre-mRNA was spliced in vitro for the time (hr) noted above each lane. The reaction products are diagramed to the left and the structures of the pre-mRNAs are diagramed below the autoradiogram. The boxes represent exons; lines represent introns. The 9-nucleotide $5^{\prime}$ splice site sequence of each transcript is written above. $(B)$ U1 snRNP binding. U1 snRNP binding reactions were terminated at the time (min) indicated above each lane. The immunoprecipitated RNase T1-resistant fragments were separated on denaturing polyacrylamide gels. The 15-nucleotide RNase T1-resistant fragment containing the 5' splice site is shown.

creased, and the authentic and one of the inserted sites are used equally.

\section{Analysis of synthetic 5' splice site utilization in the absence of the authentic 5' splice site}

We next asked whether the presence of the authentic $5^{\prime}$ splice site affected utilization of the inserted synthetic $5^{\prime}$ splice sites. The authentic 5' splice site was deleted from the constructions described above (Fig. 2B,D). In the absence of the authentic $5^{\prime}$ splice site, both the consensus and rabbit $5^{\prime}$ splice sites are active in the $\mathrm{B}$ site $(\mathrm{CB} \Delta \mathrm{l}+, \mathrm{RB} \Delta \mathrm{l}+)$. Significantly, utilization of each synthetic site increases following deletion of the authentic $5^{\prime}$ splice site (compare Fig. 2A with $2 \mathrm{~B}$ ). This result suggests that the block to efficient utilization of the sites in the original constructions is caused by the proximity of the two competing $5^{\prime}$ splice sites (the authentic and synthetic). This interpretation is supported by the analysis of the tandem consensus $5^{\prime}$ splice site insertion mutants described above. In the absence of the authentic 5' splice site, both the consensus and rabbit $5^{\prime}$ splice sites are now active in the $E$ site (CE $\Delta 1+, \operatorname{RE} \Delta 1+$; Fig. $2 \mathrm{~A})$.

In the $\mathrm{N}$ and $\mathrm{K}$ sites, the activity of the synthetic consensus and rabbit differed (Fig. 2D). In these positions, the consensus $5^{\prime}$ splice site is used at near wild-type efficiency but utilization of the rabbit site is inefficient or undetectable. Thus, in the absence of the authentic $5^{\prime}$ splice site, the synthetic consensus $5^{\prime}$ splice site is active in all positions tested whereas the activity of the synthetic rabbit $5^{\prime}$ splice site is position dependent.

Based upon these results, we conclude first that $5^{\prime}$ splice site selection is not based solely on the best match to U1 snRNA; in the presence of the authentic 5' splice site, the synthetic consensus $5^{\prime}$ splice site is not selected in three of four positions. Second, complementarity to U1 snRNA can, however, influence $5^{\prime}$ splice site selection; in comparable constructions the consensus $5^{\prime}$ splice site is more active than the rabbit $5^{\prime}$ splice site. Finally, we conclude that the sequences surrounding the authentic $5^{\prime}$ splice site (and B site) confer some advantage for splice site selection.

\section{U1 snRNP binds to both active and inactive $5^{\prime}$ splice sites}

The inactivity of the synthetic $5^{\prime}$ splice sites in some positions could be due to a failure of U1 snRNP binding. Alternatively, U1 snRNP could bind to the synthetic sites and the block to splicing occur at a subsequent 

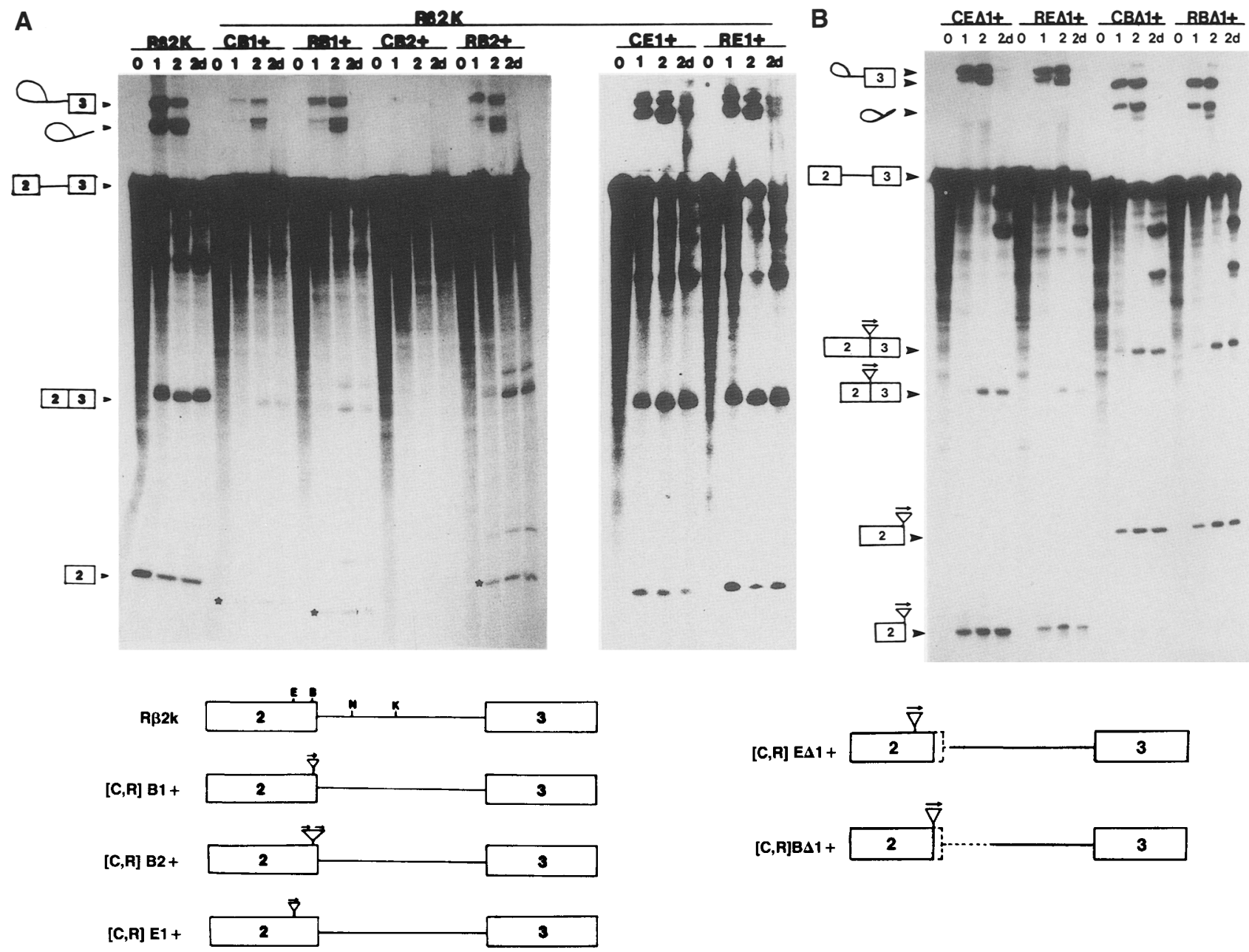

Figure 2. Splicing time course of $5^{\prime}$ splice site insertion mutants. Splicing reactions were terminated at the times (hr) indicated above each lane. A 2-hr time point of each transcript was enzymatically debranched (2d) prior to electrophoresis. The reaction products are diagramed to the left of the panel, and the constructions are diagramed below. Each construction is named according to the type of $5^{\prime}$ splice site inserted, $(C)$ consensus, $(R)$ rabbit; the position of the insertion $(E, B, N, K)$; and the number and orientation of the inserts $(1+, 2+)$. Deletions of the normal $5^{\prime}$ splice site are designatd by a $\Delta .(A) 5^{\prime}$ splice site insertions in exon 2 . The normal $\mathrm{R} \beta 2 \mathrm{~K}$ pre-mRNA is diagramed below the panel with the positions of the insertion sites marked. The stars on the panel designate the position of the linear exon splicing intermediate generated by use of the inserted $5^{\prime}$ splice sites. The size of these products differs slightly due to a small difference in the clone construction. (B) Deletions of the normal $5^{\prime}$ splice site in constructions containing exon 2 insertions. The sequences deleted are represented by dotted lines. $(C) 5^{\prime}$ splice site insertions in the intron. $(D)$ Deletions of the normal 5' splice site in constructions containing intron insertions.

step. To distinguish between these possibilities, some of the RNA substrates described above were tested for U1 snRNP binding by RNase Tl protection/immunoprecipitation using an anti-Sm antibody. Similar results were obtained using an anti-RNP antibody (data not shown).

Significantly, in every instance, Ul snRNP binds to the inserted 5' splice sites (Fig. 3A; arrowheads). Thus, binding of U1 snRNP to $5^{\prime}$ splice sites is independent of the position or the activity of the inserted synthetic $5^{\prime}$ splice site. Furthermore, consistent with the high affinity of the consensus $5^{\prime}$ splice sites for Ul snRNP (Fig. 1B), in all instances U1 snRNP binds more efficiently to the consensus than it does to the authentic or inserted synthetic rabbit 5' splice site. Based on these combined results we conclude that U1 snRNP binding may be necessary but is not sufficient for $5^{\prime}$ splice site activity.

Interestingly, in the case where two consensus sites were inserted in tandem (CB2+), one large (30-nucleotide) RNase T1-resistant fragment, which contains both inserted sites, is generated (Fig. 3A). This result strongly suggests that multiple U1 snRNPs are bound adjacent to one another. In contrast, tandem insertions of the synthetic rabbit $5^{\prime}$ splice site $(\mathrm{RB} 2+)$ do not give rise to large RNase T1-resistant fragments. To further demonstrate binding of multiple U1 snRNPs to adjacent inserted consensus $5^{\prime}$ splice sites, another construction, which contains three tandem insertions of the consensus site was analyzed. To remove the majority of the 
C

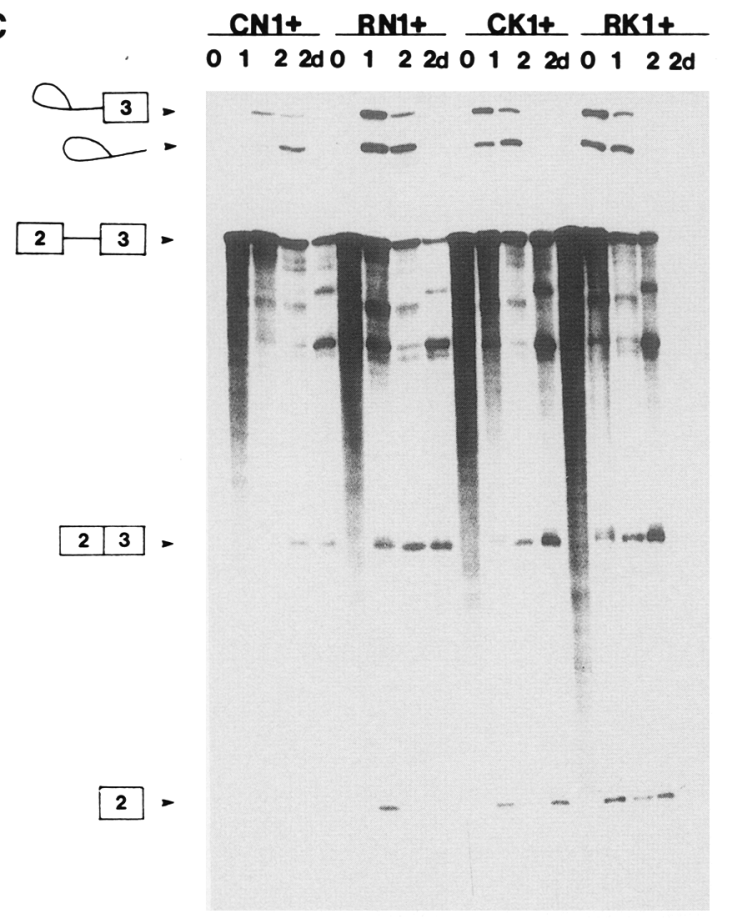

(C, R) N1+

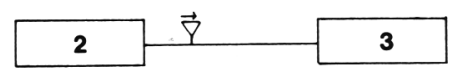

(C, R)K1+

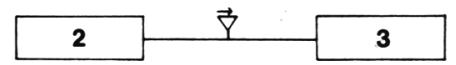

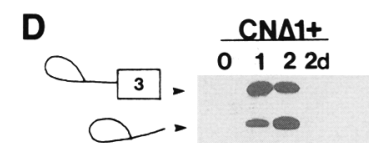

RNA1+ $0122 d$

CKA1+ RK $\Delta 1+$ $0122 d \quad 0122 d$

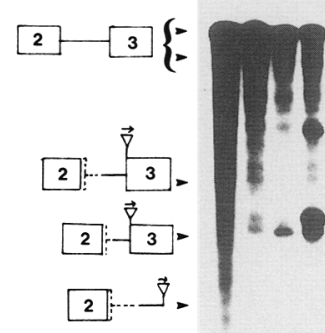

$2: \vec{Y}_{2} \quad-\infty$
[C, RI N $\Delta 1+$

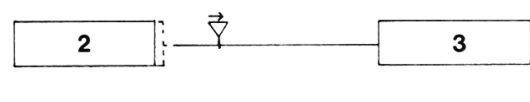

$(C, R) K \Delta 1+$

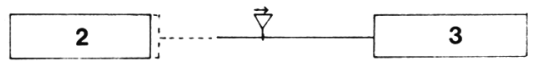

Figure 2. (cont'd.) (See facing page for legend.)

immunoprecipitated fragments and render the protected 5 ' splice sites more obvious, transcripts were truncated at the $\mathrm{N}$ site. The protection data clearly demonstrate that the major protected fragment increases in size proportionally as the number of consensus sites increases, strongly suggesting that each inserted consensus site is bound by U1 snRNP (Fig. 3B). The binding of multiple Ul snRNPs to adjacent nine nucleotide sequences is surprising given the large size of Ul snRNP particles.

\section{Splicing complex assemby of $5^{\prime}$ splice site insertion mutants}

The experiments described above indicate that the inactivity of inserted synthetic $5^{\prime}$ splice sites is not due to a lack of Ul snRNP binding. To delineate the specific step (or steps) responsible for the splicing defect, we next analyzed the ability of these mutant RNAs to assemble into splicing complexes. The stepwise assembly of mammalian splicing complexes can be monitored by electrophoretic separation on non-denaturing gels (Konarska and Sharp 1986). Pre-mRNA substrates form at least two time- and ATP-dependent ribonucleoprotein (RNP) complexes (Fig. 4, bands A and B) (Konarska and Sharp 1986). The earliest specific RNP complex detected, band A, contains U2 snRNP, which is bound to the branch point. An RNP complex detected at later times, band B, contains U2 snRNP as well as U4, U5, and U6 snRNPs and is (or is related tol the active splicing complex, since it contains the splicing intermediates (Konarska and Sharp 1986; K.K. Nelson and M.R. Green, unpubl.). U1 snRNP is not present in this gel system presumably due to the heparin pretreatment (Bindereif and Green 1987).

Initial experiments demonstrated that the rabbit $\beta$ globin RNA substrates are sub-optimal for splicing complex assembly studies; these long RNA substrates form slowly migrating non-specific complexes, making the detection and resolution of specific complexes difficult (data not shown). To eliminate this problem, a series of chimeric constructions were made, comprised of the rabbit $\beta$-globin exon 2 and the $5^{\prime} 117$ or 163 nucleotides of IVS2 joined to the human $\beta$-globin 3 ' 55 nucleotides of IVS1 and exon 2 (Fig. 4A). The splicing patterns of 
A

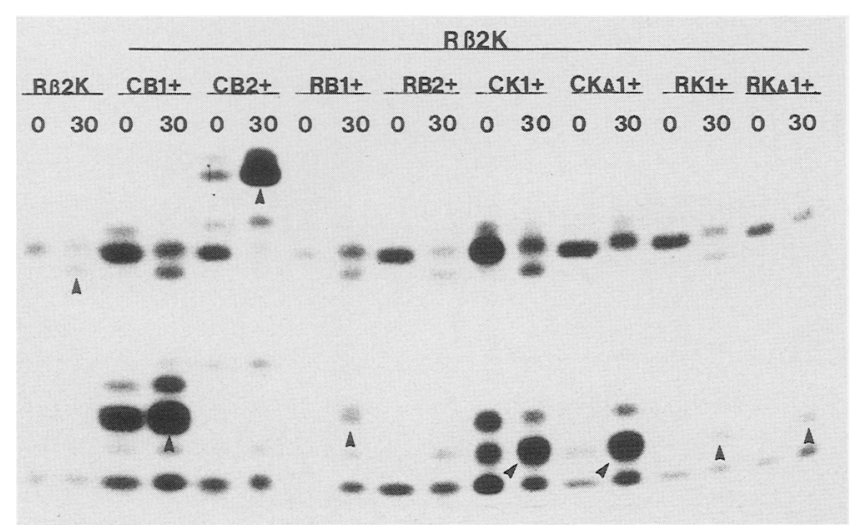

B

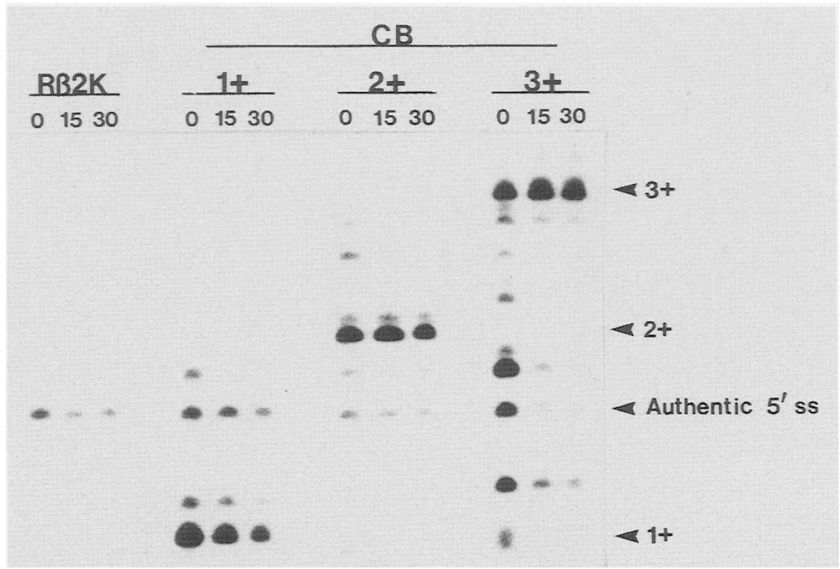

Figure 3. RNase T1 protection/immunoprecipitation of $5^{\prime}$ splice site insertion mutants. (A) Full-length pre-mRNAs. The reactions were terminated at the times $(\mathrm{min})$ indicated above each lane. The RNase T1-resistant fragments containing the $5^{\prime}$ splice sites are indicated by an arrowhead at the 30-min time point. The normal 5' splice site fragment is marked only in the R $\beta 2 \mathrm{~K}$ lanes. There is no detectable protection of the inserted 5' splice sites in the RB2 + lanes. (B) Analysis of single and multiple insertions in the B site. The RNA transcripts were run-off at the $\mathrm{N}$ site. The number of inserted 5' splice sites protected from RNase Tl digestion is indicated on the right.

these chimeric constructs are similar to those of the original rabbit constructions (data not shown).

Figure 4A displays the ribonucleoprotein complexes formed with substrates containing the synthetic $5^{\prime}$ splice sites inserted in the $\mathrm{N}$ site and deleted for the authentic $5^{\prime}$ splice site $(\mathrm{CN} \Delta 1+, \mathrm{RN} \Delta 1+)$. The RNA substrate containing the consensus $5^{\prime}$ splice site in the $\mathrm{N}$ site $(\mathrm{CN} \Delta \mathrm{l}+)$ is efficiently assembled into both band A and B RNP complexes, as expected from its wild-type splicing efficiency. In contrast, the RNA substrate containing the rabbit $5^{\prime}$ splice site in the $\mathrm{N}$ site forms the band A complex normally but is severely defective in band $\mathrm{B}$ complex formation. To prove that this defect was at the level of band B complex formation and not in Ul snRNP binding, these chimeric pre-mRNAs and the corresponding pre-mRNAs containing the authentic $5^{\prime}$ splice site were subjected to RNase Tl protection analysis (Fig. 4B). The data clearly demonstrate that the inserted sites are protected at similar levels to those found in the previously tested pre-mRNAs (Fig. 3A). Therefore, we conclude that the splicing defect in RN $\Delta 1+$ can be attributed (at least in part) to inefficient formation of the band B RNP complex.

We next analyzed the B site insertion mutants (Fig. $4 \mathrm{C})$. Though transcripts containing the rabbit or consensus synthetic $5^{\prime}$ splice sites inserted in the B site are spliced inefficiently, their activity in complex formation is remarkably similar to the wild-type pre-mRNA. Both bands $\mathrm{A}$ and $\mathrm{B}$ are formed with normal efficiency, although the band $\mathrm{B} /$ band $\mathrm{A}$ ratio is less than that observed with the wild-type substrate. Analysis of the RNA processing products in band $B$ indicates a significant deficiency of splicing intermediates (Fig. 4D). Thus, the block to efficient splicing of the single insertion mutants in the B site occurs at a step subsequent to band B complex formation.
Splicing of the $5^{\prime}$ splice site tandem insertion mutants is blocked at a step different from the single insertion mutants. RNA substrates containing tandem consensus $5^{\prime}$ splice site insertions in the B site $(\mathrm{CB} 3+)$, which like the $\mathrm{CB} 2+$ mutant (Fig. 2A) are not spliced, form higher levels of band A than the wild-type pre-mRNA. However, these RNA substrates form very low levels of the band B complex. In contrast, RNA substrates containing tandem rabbit $5^{\prime}$ splice site insertions in the $B$ site (RB3 +), which are spliced (data not shown), form normal levels of band B. Thus, for tandem consensus insertion mutants, the block to splicing occurs at or before the transition from the band A to band B RNP complex.

\section{Analysis of $3^{\prime}$ splice site insertion mutants}

To determine the activity of a synthetic $3^{\prime}$ splice site we inserted it into multiple positions in the previously characterized mutant $\mathrm{H} \beta^{\triangle \mathrm{PyAG}}$ (Ruskin and Green 1985a). This deletion mutant completely lacks the $3^{\prime}$ splice site consensus sequence; cryptic 3 ' splice sites are not activated and, thus, $\mathrm{H} \beta{ }^{\triangle \mathrm{PyAG}}$ is severely defective in both the first and second steps of splicing (Ruskin and Green 1985a). The synthetic $3^{\prime}$ splice site is used efficiently when inserted in the $H \beta^{\Delta{ }^{\text {PyAG }}} \mathrm{K}$ site $\left(3^{\prime} \mathrm{K}\right)$, near the normal position of the $3^{\prime}$ splice site, or the A site (3'A), 11 nucleotides downstream of the K site (Fig. 5A). However, insertion of the synthetic $3^{\prime}$ splice site an additional 12 nucleotides downstream from the $A$ to the $S$ site $\left(3^{\prime} S\right)$ leads to a dramatic decrease in splicing efficiency. Likewise, insertion of the synthetic $3^{\prime}$ splice site in the exon $2 \mathrm{D}$ site $\left(3^{\prime} \mathrm{D}\right)$ results in an RNA substrate that is completely defective for splicing. These results indicate that similar to $5^{\prime}$ splice site selection, $3^{\prime}$ splice site selection is very dependent upon the context in which the splice site resides. In particular, the normal 
position appears to provide a context that favors the selection of the site.

\section{Binding of factors to $3^{\prime}$ splice site insertion mutants}

A $70-100-\mathrm{kD}$ protein $170-\mathrm{kD}$ RNA binding protein, $\mathrm{RBP}$ ) that contains an Sm determinant and is probably associated with U5 snRNP specifically binds to the $3^{\prime}$ splice site (Gerke and Steitz 1986; Tazi et al, 1986). The binding specificity and inability to bind mutant $3^{\prime}$ splice sites suggests that this protein is a splicing factor (Gerke and Steitz 1986; Tazi et al. 1986). To determine the relationship between $3^{\prime}$ splice site activity and binding of the $70-\mathrm{kD} \mathrm{RBP}$, we analyzed the $\mathrm{H} \beta^{\Delta \mathrm{PyAG}} 3^{\prime}$ splice site insertion mutants using an RNase $\mathrm{T} 1 /$ immunoprecipitation assay (Gerke and Steitz 1986). We find that the $70-\mathrm{kD}$ RBP binds to the synthetic $3^{\prime}$ splice site regardless of position or utilization (Fig. 5B). Thus, like the $5^{\prime}$ splice site, binding of a splicing factor(s) to the $3^{\prime}$ splice site may be necessary but is not sufficient for splice site selection.

\section{Conclusions}

\section{The role of context in splice site selection}

Several ideas have been advanced to explain how authentic splice sites are distinguished from sequences within exons and introns that resemble splice junctions. First, some results suggest that splice sites may be selected based primarily on match to the consensus (Zhuang and Weiner 1986; Aebi et al. 1987; Ohshima and Gotoh 1987; Zhuang et al. 1987). In fact, in most instances the authentic splice site is a better match to the consensus than other sequences within exons and introns (Ohshima and Gotoh 1987). Second, various scanning models have been proposed. These models invoke a splicing factor (or factors) that binds to a specific pre-mRNA region and scans the RNA unidirectionally (either $5^{\prime}$ to $3^{\prime}$ or $3^{\prime}$ to $\left.5^{\prime}\right)$ until a $\left(5^{\prime}\right.$ or $\left.3^{\prime}\right)$ splice site is encountered (Sharp 1981; Lang and Spritz 1983). Third, it has been suggested that functional $5^{\prime}$ and $3^{\prime}$ splice sites closest to one another have an advantage in selec-
A

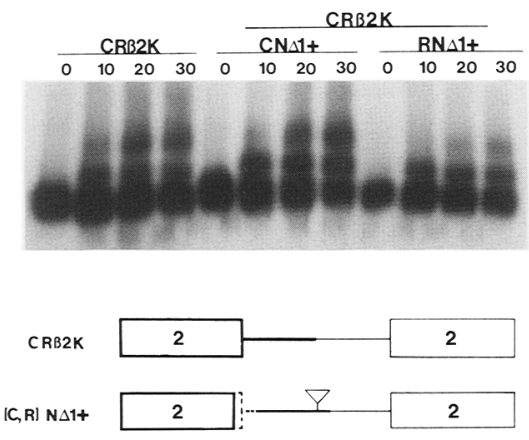

C

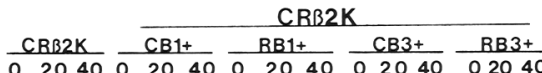

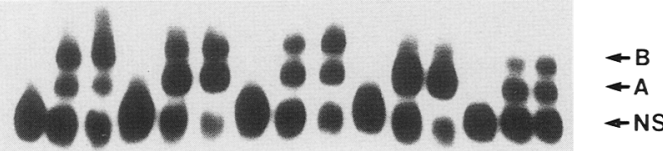

CRB2K

B

2

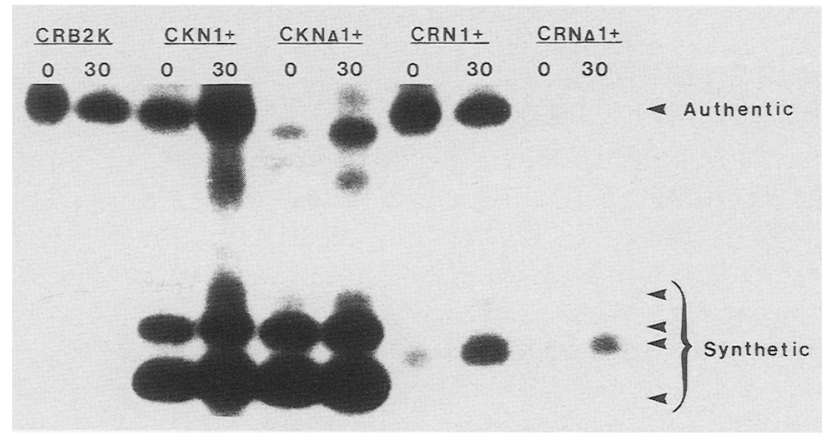

122,345
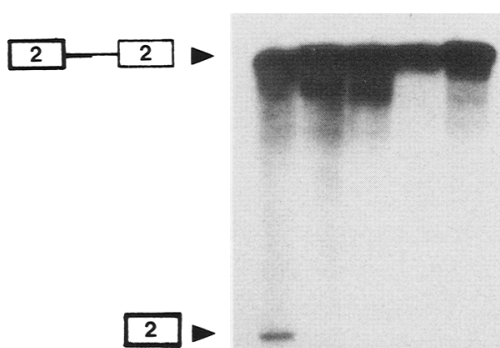

Figure 4. Analysis of splicing complex formation of splice site insertions mutants. $(A)$ Insertions in the N site lacking the authentic $5^{\prime}$ splice site. Splicing reactions were incubated for the times $(\mathrm{min})$ indicated, aliquots were removed, and the reaction was stopped by the addition of heparin. Splicing complexes were separated on native composite gels. The structures of the transcripts are diagrammed below the panel. Thick lines represent rabbit $\beta$-globin sequences; thin lines represent human $\beta$-globin sequences. Dotted lines represent deleted sequences. (NS) non-specific. (B) U1 snRNP binding. The names of the pre-mRNAs are indicated at the top. The binding reactions were allowed to proceed for the time $(\mathrm{min})$ indicated above each lane. The RNase T1-resistant fragments containing the authentic and inserted synthetic 5' splice sites are indicated on the right. The fragment seen just below the position of the authentic $5^{\prime}$ splice site in the CKN $\Delta 1+$ lanes is a non-specific fragment that contains neither the authentic nor synthetic $5^{\prime}$ splice site. $(C)$ Insertions in the B site in the presence of the authentic $5^{\prime}$ splice site. Experimental procedure is the same as in Fig. 4A. The structure of the normal gene is diagramed below with the position of the insertion noted. $(D)$ Analysis of RNA species in band B. The RNA from the band B region of each $40-\mathrm{min}$ time point was electroeluted and analyzed by denaturing polyacrylamide gel electrophoresis. The identity of the bands is diagrammed to the left. Lanes: (1) CR $\beta 2 K_{;}(2) \mathrm{CB} 1+$; (3) RB1 + ; (4) CB3 + ; (5) RB3 +. 
A

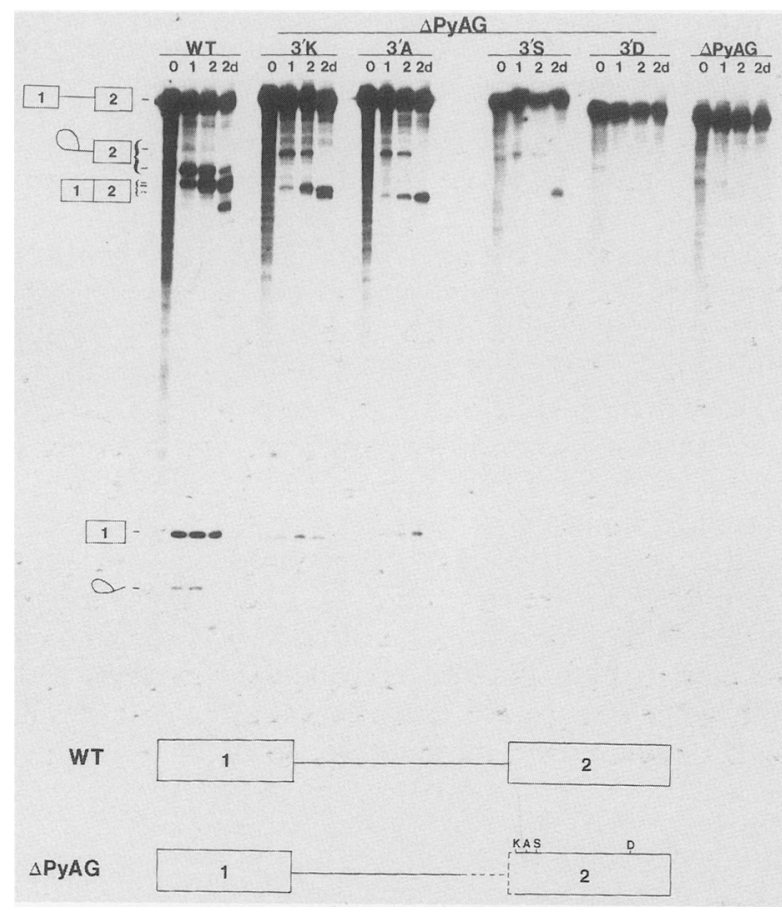

B

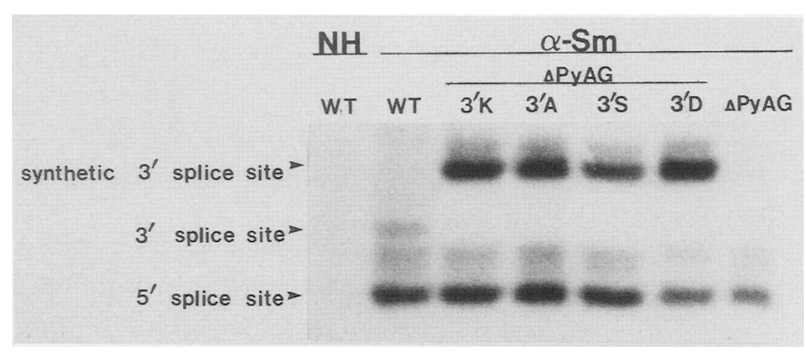

Figure 5. Analysis of synthetic $3^{\prime}$ splice site insertion mutants. (A) Splicing. Splicing reactions were carried out as described in Fig. 2. The constructs are named according to the position of the inserted synthetic $3^{\prime}$ splice site in $\triangle$ PyAG: $3^{\prime}$, $3^{\prime} \mathrm{A}, 3^{\prime} \mathrm{S}$, and $3^{\prime} \mathrm{D}$. The insertion sites are marked in the diagram of $\triangle$ PyAG below. The deletion of the polypyrimidine tract and the AG is designated by a dotted line. The structure of the RNA processing products are shown on the left. $(B) 70-\mathrm{kD}$ RBP binding. Immunoprecipitation of inserted $3^{\prime}$ splice sites. The experiments were carried out as described in Fig. 3 . The identities of the RNase T1-resistant fragments are indicated on the left.

nificantly, these mutations often lead to the activation of cryptic splice sites, which are often located near the mutated authentic site (Treisman et al. 1983; Green 1986; Padgett et al. 1986).

When in the proximity of the authentic site, match to the consensus appears to play a role in $5^{\prime}$ splice site selection. For example, when the synthetic rabbit $5^{\prime}$ splice site is inserted in the B site, it is used with equal efficiency to the completely homologous authentic site. In contrast, when the consensus $5^{\prime}$ splice site is inserted in this position, it is used exclusively (Fig. 2A). In agreement with our in vitro splicing results are in vivo experiments in which consensus or rabbit synthetic $5^{\prime}$ splice sites were inserted in the B site of the rabbit $\beta$-globin gene. Significantly, these in vivo results were the same as our in vitro results (Eperon et al. 1986).

The selection of a $5^{\prime}$ splice site within the permissive context may be based on the stability of the U1 snRNP interaction with the competing sites. Functional splicing complex formation may not occur in the presence of multiple closely bound U1 snRNP particles; splicing would thus be blocked unless only one Ul snRNP is present. In the case of the consensus insertion in the B site, this would favor the use of the inserted site since the interaction of U1 snRNP with this site is more stable. The rabbit $5^{\prime}$ splice site insertion in the B site would result in a pre-mRNA that is spliced at both sites since the interaction of Ul snRNP is equivalent. Significantly, these predictions are consistent with the observed results.

The region surrounding the authentic $3^{\prime}$ splice site also appears to confer an advantage for $3^{\prime}$ splice site selection. One of the most dramatic results is the signifi- 
cant decrease in splicing efficiency when the synthetic $3^{\prime}$ splice site is moved 12 nucleotides downstream from the $A$ to the $S$ site in human $\beta$-globin (Fig. 5B). It is unlikely that the inactivity of the synthetic $3^{\prime}$ splice site in the $\mathrm{S}$ site is due to a lack of an acceptable branch point since there are several suitable adenosine residues within the appropriate range for RNA branch formation (reviewed in Green 1986). Furthermore, when a DNA fragment containing a functional synthetic $3^{\prime}$ splice site and branch point is inserted in the S site, the inserted $3^{\prime}$ splice site is also inactive (K.K. Nelson and M.R. Green, unpubl.). We note that it has been reported that a synthetic $3^{\prime}$ splice site is active in vivo when inserted into several positions (Rautmann et al. 1984). However, in this study there was no measure of splicing efficiency. For example, we would not detect use of the synthetic site if it were utilized at 50-fold lower efficiency than the authentic site.

The results of other studies are also consistent with the notion that context plays a major role in splice site selection. For example, in yeast a deletion of intron sequences near but not including the $5^{\prime}$ splice site consensus sequence decreases splicing efficiency in vivo (Pikielny and Rosbash 1985). Furthermore, mutations within exons can affect alternative splicing of SV40 premRNA (Somasekhar and Mertz 1985), and exon deletions can dramatically decrease splicing efficiency (Furdon and Kole 1986; Parent et al. 1987). Moreover, exon sequences can affect splice site utilization of tandem splice site mutants (Reed and Maniatis 1986). Taken together, these results indicate that the sequences flanking authentic splice junctions affect selection.

The major question then is what feature of the regions flanking authentic splice sites favors their utilization, or conversely, why are the synthetic splice sites not utilized in other positions? There are at least two possible explanations for this observed context effect. First, flanking sequences may contain a primary sequence element(s) that has not yet been delineated. This putative primary sequence element would have to be highly degenerate or dispersed since it has not been identified in several computer-generated searches (Mount 1982; Ohshima and Gotoh 1987; Shapiro and Senapathy 1987). Alternatively, the context effect may result from a local secondary or tertiary structure that facilitates efficient splice site utilization.

\section{Binding of splicing factors}

Our results show that specific binding of splicing factors, U1 snRNP and the 70-kD RBP, is not sufficient for splice site utilization. In all instances the inserted synthetic sites are bound by their respective factors, but in the majority of cases the inserted sites are inactive. Similarly, in another study, U1 snRNP was found to bind to a mutant, inactive $5^{\prime}$ splice site /Chabot and Steitz 1987b/. Our binding experiments show that the inactivity of the synthetic splice sites is not due to an unfavorable secondary structure that renders them inac- cessible to splicing components. Along these lines, other studies have demonstrated that splice sites can be active even when sequestered in long hairpin loops (Solnick 1985).

Interestingly, a synthetic $5^{\prime}$ or $3^{\prime}$ splice site inserted between the authentic splice junctions does not affect splicing efficiency, even though splicing factors are bound to these inserted sites. These results suggest that splicing either does not involve a tracking mechanism that moves nucleotide-by-nucleotide along the RNA, or that such a tracking mechanism efficiently removes such obstacles.

Though context independent, U1 snRNP binding is highly sequence dependent. Binding of U1 snRNP to the consensus $5^{\prime}$ splice site is at least 10 -fold higher than it is to the rabbit $5^{\prime}$ splice site, which differs from the consensus at three positions (Fig. 3A). This large difference in observed binding is consistent with the significant $-2.7 \mathrm{kcal} / \mathrm{mole}$ difference in $\Delta G$ values for the $\mathrm{U} 1$ snRNA-5' splice site interactions at the two sites (Freier et al. 1986).

Our results also demonstrate that multiple U1 snRNPs can simultaneously bind to a pre-mRNA. The RNase T1 protection analysis of the tandem $5^{\prime}$ splice site consensus insertions indicates that two U1 snRNPs are bound to adjacent 9-nucleotide sequences (Fig. 3A,B). This result strongly suggests that multiple U1 snRNPs can also bind to a single pre-mRNA when the $5^{\prime}$ splice sites are separated.

\section{Splicing complex formation can be blocked at two steps}

Assembly of a functional splicing complex involves the direct or indirect ordered association of the U1, U2, U4, U5, and U6 snRNPs with the pre-mRNA /Grabowski and Sharp 1986; Konarska and Sharp 1986; Bindereif and Green 1987). First, the U1 and U2 snRNPs bind to the $5^{\prime}$ splice site and branch point, respectively; it is likely that bound U1 and U2 snRNPs then interact with one another (Chabot and Steitz 1987a). Subsequently, the U4, U5, and U6 snRNPs bind to the initial splicing complex, primarily by interaction with bound $U 1$ and $U 2$ snRNPs (Bindereif and Green 1987). The addition of U4, U5, and U6 snRNPs can be monitored by analysis of splicing complexes on non-denaturing gels (band $\mathrm{A}$ to band $\mathrm{B}$ complex; Konarska and Sharp 1986).

The splice site insertion mutants reveal blocks at two distinct steps in splicing complex assembly. First, some mutants are blocked at the band $\mathrm{A}$ to band $\mathrm{B}$ transition. The most striking example of this is the tandem consensus $5^{\prime}$ splice sites in the B site (CB3+, Fig. 4C). This transcript, which is not spliced in vitro, forms band $\mathrm{A}$ normally but does not form band B. It is likely that this block is due to steric hinderance resulting from multiple U1 snRNPs bound at the tandem 5 ' splice sites. The multiple bound U1 snRNPs could sterically interfere with either the U1 snRNP-U2 snRNP interaction, or association of U4, U5, and U6 snRNPs with bound $U 1$ and U2 snRNPs.

The RN $\Delta 1+$ mutant is defective in splicing also due 
to a partial inability to form band $\mathrm{B}$. The unfavorable context of the $\mathrm{N}$ site thus affects splicing by preventing efficient band B formation. Again, this could be due to inefficient U1 snRNP-U2 snRNP interaction or inefficient binding of U4, U5, and U6 snRNPs. Significantly, in this same position, the consensus $5^{\prime}$ splice site is active and the RNA substrate forms band B efficiently (Fig. 4A). U1 snRNP binds much more efficiently to the consensus than to the rabbit $5^{\prime}$ splice site (Fig. 3A), and thus it is more probable that U1 snRNP is bound to the consensus site at any time. The increased probability of U1 snRNP binding may compensate for the inefficiency of band $B$ formation due to inappropriate context.

A second block in splicing can occur subsequent to band $\mathrm{B}$ formation $(\mathrm{CB} 1+, \mathrm{RB} 1+$, Fig. $4 \mathrm{C})$. Band $\mathrm{B}$ forms efficiently with these substrates but the splicing intermediates are present at far below wild-type levels. Although the electrophoretic mobility of band B is apparently normal, in these instances the precise composition or conformation of splicing factors may be abnormal, and thus efficient splicing does not occur. Future studies will focus on using these and other mutants to study in further detail the relationship between splice site selection and splicing complex assembly.

\section{Materials and methods \\ Materials}

Restriction enzymes are from New England Biolabs, Promega Biotech, Boehringer Mannheim Biochemicals, and Brisco Ltd. RNase T1 was purchased from Calbiochem, Protein A Sepharose from Pharmacia, and RNAsin, SP6 RNA polymerase, DNase I, and DNA ligase from Promega Biotech. ${ }^{32} \mathrm{P}-\mathrm{UTP}$ and the site-directed mutagenesis kit were purchased from Amersham. The anti-Sm antibody was obtained from the Centers for Disease Control, Atlanta, Georgia, USA.

\section{Constructions}

$\mathrm{R} \beta 2 \mathrm{~K}$ was constructed by inserting the $\mathrm{Ncol}(+289)$ to $\mathrm{Bg} / \mathrm{II}$ $(+1196)$ fragment of the rabbit $\beta$-globin genomic clone la gift of Julian Banerii) between the EcoRI and BamHI sites of pSP65. A $K p n I$ linker was inserted into the ScaI site $(+773)$. The resulting clone contained the majority of the rabbit $\beta$-globin second and third exons and IVS2.

All insertion mutants were constructed by cutting $\mathrm{R} \beta 2 \mathrm{~K}$ or $\mathrm{H} \beta^{\Delta \mathrm{PyAG}}$ with an appropriate restriction enzyme, BamHI (B), $\operatorname{EspI}(\mathrm{E}), \operatorname{NcoI}(\mathrm{N}), \operatorname{KpnI}(\mathrm{K}), \operatorname{AccI}(\mathrm{A}), \operatorname{SinI}(\mathrm{S}), \operatorname{DraIII}(\mathrm{D})$, and generating blunt ends. Ligations were carried out using a $400: 1$ molar excess of the synthetic double-stranded oligonucleotide to the plasmid DNA. All insertions were confirmed by DNA sequencing (Maxam and Gilbert 1980). Deletions of normal 5' splice sites extend as follows: $5^{\prime} \mathrm{E}$ and $\mathrm{N}$ insertions deleted from +476 and $+505 ; 5^{\prime} \mathrm{K}$ and $\mathrm{B}$ from +476 to +613 .

The chimeric constructions used in the complex formation studies have as a common vector the SphI, XbaI fragment of NL-X (Ruskin et al. 1985) which contains the second exon and 55 nucleotides of human $\beta$-globin IVS1. The inserts are either Sphl, NcoI fragments, or SphI, HincII fragments of the appropriate insertion constructions.

\section{Site-directed mutagenesis}

Single-stranded DNA was made from M13mpl9 containing the HindIII-BamHI fragment of pSP64H $\beta \Delta 6$. Mutagenesis was carried out according to Amersham oligonucleotide-directed in vitro mutagenesis system. Sequences were confirmed by dideoxy sequencing of SP6-generated RNA.

\section{In vitro transcription, splicing, and debranching reactions}

All human $\beta$-globin templates were linearized with BamHI, and the rabbit templates with $X b a I$. Shortened transcripts were made by using templates cut at the $N c o$ I site. Transcriptions and in vitro splicing procedures were carried out as described (Krainer et al. 1984; Ruskin et al. 1984). Enzymatic debranching reactions were carried out as described (Ruskin and Green $1985 b)$.

\section{RNase T1 protection/immunoprecipitation assays}

Procedure was carried out as described (Black et al. 1985; Chabot et al. 1985) or was modified by altering the RNase Tl level to 5 units and incubating the digest at $30^{\circ} \mathrm{C}$ for $5 \mathrm{~min}$.

\section{Electrophoretic analysis of splicing complexes}

Procedures were carried out as described (Konarska and Sharp 1986) with the following modifications. Aliquots of $5 \mu \mathrm{l}$ of a standard $25-\mu l$ splicing reaction were removed at the indicated times and added to $1 \mu \mathrm{l}$ of $5 \mathrm{mg} / \mathrm{ml}$ heparin solution. Samples were allowed to sit at room temperature until the time course was finished. Two microliters of loading solution $10.3 \times \mathrm{TBE}$, $50 \%$ glycerol, $0.1 \%$ xylene cyanol FF, $0.1 \%$ bromphenol blue) were added and the sample was loaded on the gel. The gel was $3.5 \%$ polyacrylamide, $0.5 \%$ agarose, $10 \%$ glycerol, $0.3 \times \mathrm{TBE}$. Running buffer was $0.3 \times$ TBE. The gel was pre-run $30-60 \mathrm{~min}$ at $60 \mathrm{~V}$ and run at $175 \mathrm{~V}$ for $4-5 \mathrm{hr}$.

\section{Acknowledgments}

We are extremely grateful for the excellent technical assistance of Maureen McCaffrey. We would also like to thank Michael Rosbash and members of the Green lab for useful suggestions and constructive criticisms. K.K.N. was supported by a National Institutes of Health predoctoral training grant. This work was supported by grants from the National Institutes of Health and The Chicago Community Trust/Searle Scholars Program to M.R.G.

\section{References}

Aebi, M., H. Hornig, and C. Weissmann. 1987. 5' Cleavage site in eukaryotic pre-mRNA splicing is determined by the overall $5^{\prime}$ splice region, not by the conserved GU. Cell 50: $237-246$.

Bindereif, A. and M.R. Green. 1987. An ordered pathway of snRNP binding during mammalian splicing complex assembly. $E M B O$ J. 6: 2415-2424.

Black, D.L., B. Chabot, and J.A. Steitz. 1985. U2 as well as U1 small nuclear ribonucleoproteins are involved in premessenger RNA splicing. Cell 42: 737-750.

Chabot, B. and J.A. Steitz. 1987a. Multiple interactions between the splicing substrate and small nuclear ribonucleoproteins in splicesomes. Mol. Cell. Biol. 7: 281-293. $-1987 \mathrm{~b}$. Recognition of mutant and cryptic $5^{\prime}$ splice sites 
by the U1 small nuclear ribonucleoprotein in vitro. Mol. Cell. Biol. 7: 698-707.

Chabot, B., D.L. Black, D.M. LeMaster, and J.A. Steitz. 1985. The $3^{\prime}$ splice site of pre-messenger RNA is recognized by a small nuclear ribonucleoprotein. Science 230: 1344-1349.

Eperon, L.P., J.P. Estibeiro, and I.C. Eperon. 1986. The role of nucleotide sequences in splice site selection in eukaryotic pre-messenger RNA. Nature 324: 280-282.

Freier, S.M., R. Kierzek, J.A. Jaeger, N. Sugimoto, M.H. Caruthers, T. Neilson, and D.H. Turner. 1986. Improved freeenergy parameters for predictions of RNA duplex stability. Proc. Natl. Acad. Sci. 83: 9373-9377.

Furdon, P.J. and R. Kole. 1986. Inhibition of splicing but not cleavage at the $5^{\prime}$ splice site by truncating human $\beta$-globin pre-mRNA. Proc. Natl. Acad. Sci. 83: 927-931.

Gerke, V. and J.A. Steitz. 1986. A protein associated with small nuclear ribonucleoprotein particles recognizes the $3^{\prime}$ splice site of premessenger RNA. Cell 47: 973-984.

Grabowski, P.J. and P.A. Sharp. 1986. Affinity chromatography of splicing complexes: U2, U5, and U4 + U6 small nuclear ribonuclear protein particles in the nucleosome. Science 233: $1294-1299$.

Green, M.R. 1986. Pre-mRNA splicing. Annu. Rev. Genet. 20: $671-708$.

Konarska, M.M. and P.A. Sharp. 1986. Electrophoretic separation of complexes involved in the splicing of precursors to mRNAs. Cell 46: 845-855.

Krainer, A.R., T. Maniatis, B. Ruskin, and M.R. Green. 1984. Normal and mutant human $\beta$-globin pre-mRNAs are faithfully and efficiently spliced in vitro. Cell 36: 993-1005.

Kuhne, T., B. Wieringa, J. Reiser, and C. Weissmann. 1983. Evidence against a scanning model of RNA splicing. EMBO $I$. 2: $727-733$.

Lang, K.M. and R.A. Spritz. 1983. RNA splice site selection: Evidence for a $5^{\prime}-3^{\prime}$ scanning model. Science 220: 13511355.

Maniatis, T. and R. Reed. 1987. The role of small nuclear ribonucleoprotein particles in pre-mRNA splicing. Nature 325: $673-678$.

Maxam, A.M. and W. Gilbert. 1980. Sequencing end-labeled DNA with base-specific chemical cleavages. Methods Enzymol. 65: 499-560.

Mount, S.M. 1982. A catalogue of splice junction sequences. Nucleic Acids Res. 10: 459-472.

Ohshima, Y. and Y. Gotoh. 1987. Signals for the selection of a splice site in pre-mRNA. I. Mol. Biol. 195: 247-259.

Padgett, R.A., P.J. Grabowski, M.M. Konarska, and P.A. Sharp. 1986. Splicing of messenger RNA precursors. Annu. Rev. Biochem. 55: 1119-1150.

Parent, A., S. Zeitlin, and A. Efstratiadis. 1987. Minimal exon sequence requirements for efficient in vitro splicing of mono-intronic nuclear pre-mRNA. $I$. Biol. Chem. 262: 11284-11291.

Pikielny, C.W. and M. Rosbash. 1985. mRNA splicing efficiency in yeast and the contribution of non-conserved sequences. Cell 41: 119-126.

Rautmann, G., H.W.D. Matthes, M.J. Gait, and R. Breathnach. 1984. Synthetic donor and acceptor splice sites function in an RNA polymerase B (II) transcription unit. $E M B O /$. 3: 2021-2028.

Reed, R. and T. Maniatis. 1986. A role for exon sequences and splice-site proximity in splice-site selection. Cell 46: 681690.

Ruskin, B. and M.R. Green. 1985a. Role of $3^{\prime}$ splice site consensus sequence in mammalian pre-mRNA splicing. Nature 317: $732-734$. 1985b. Detection and characterization of an RNA processing activity that debranches RNA lariats. Science 229: $135-140$.

Ruskin, B., A.R. Krainer, T. Maniatis, and M.R. Green. 1984. Excision of an intact intron as a novel lariat structure during pre-mRNA splicing in vitro. Cell 38: 317-331.

Ruskin, B., J.M. Greene, and M.R. Green. 1985. Cryptic branchpoint activation allows accurate in vitro splicing of human $\beta$-globin intron mutants. Cell 41: 833-844.

Ruskin, B., P.D. Zamore, and M.R. Green. 1988. A factor, $\mathrm{U} 2 \mathrm{AF}$, is required for $\mathrm{U} 2 \mathrm{snRNP}$ binding and splicing complex assembly. Cell 52: 207-219.

Shapiro, M.B. and P. Senapathy. 1987. RNA splice junctions of different classes of eukaryotes: Sequence statistics and functional implications in gene expression. Nucleic Acids Res. 15: 7155-7174.

Sharp, P.A. 1981. Speculations on RNA splicing. Cell 23: 643646.

- 1987. Splicing of messenger RNA precursors. Science 235: 766-771.

Solnick, D. 1985. Alternative splicing caused by RNA secondary structure. Cell 43: 667-676.

Somasekhar, M.B. and J.E. Mertz. 1985. Exon mutations that affect the choice of splice sites used in processing the SV40 late transcripts. Nucleic Acids Res. 13: 5591-5609.

Taylor, J.W., J. Ott, and F. Eckstein. 1985. The rapid generation of oligonucleotide-directed mutations at high frequency using phosphorothioate-modified DNA. Nucleic Acids Res. 13: 8765-8785.

Tazi, J., C. Alibert, J. Temsamani, I. Reveillaud, G. Cathala, C. Brunel, and P. Jeanteur. 1986. A protein that specifically recognizes the $3^{\prime}$ splice site of mammalian pre-mRNA introns is associated with small nuclear ribonucleoprotein. Cell 47: 755-766.

Treisman, R., S.H. Orkin, and T. Maniatis. 1983. Structural and functional defects in $\beta$-thalassemia. In Globin gene expression and hematopoietic differentiation (ed. G. Stamatoyanopoulos and A.W. Nienhuis\}, pp. 99-121. Liss, New York.

Zhuang, Y. and A.M. Weiner. 1986. A compensatory base change in Ul snRNA suppresses a $5^{\prime}$ splice site mutation. Cell 46: 827-835.

Zhuang, Y., H. Leung, and A.M. Weiner. 1987. The natural 5' splice site of Simian Virus 40 large $\mathrm{T}$ antigen can be improved by increasing the base complementarity to Ul RNA. Mol. Cell. Biol. 7: 3018-3020. 


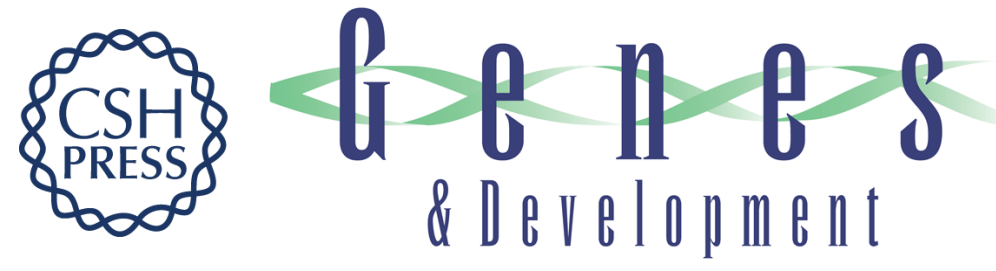

\section{Splice site selection and ribonucleoprotein complex assembly during in vitro pre-mRNA splicing.}

K K Nelson and M R Green

Genes Dev. 1988, 2:

Access the most recent version at doi:10.1101/gad.2.3.319

References This article cites 39 articles, 11 of which can be accessed free at:

http://genesdev.cshlp.org/content/2/3/319.full.html\#ref-list-1

License

Email Alerting Receive free email alerts when new articles cite this article - sign up in the box at the top Service right corner of the article or click here.

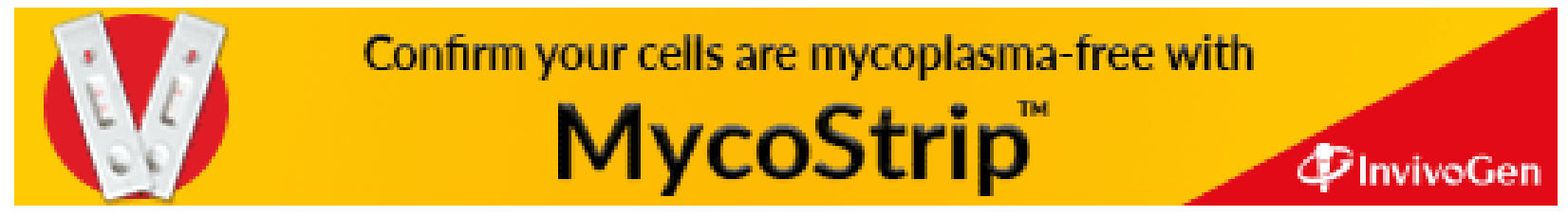

